\title{
Enhancing Student Learning Through Accreditation
}

\section{Dr. Ronald W. Welch, The Citadel}

Ron Welch (P.E.) received his B.S. degree in Engineering Mechanics from the United States Military Academy in 1982. He received his M.S. and Ph.D. degrees in Civil Engineering from the University of Illinois, Champaign-Urbana in 1990 and 1999, respectively. He became the Dean of Engineering at The Citadel on 1 July 2011. Prior to his current position, he was the Department Head of Civil Engineering at The University of Texas at Tyler from Jan 2007 to June 2011 as well as served in the Corps of Engineers for over 24 years including eleven years on the faculty at the United States Military Academy.

\section{Dr. Tara Hornor, The Citadel}

Dr. Tara Hornor currently serves as Associate Provost for Planning, Assessment and Evaluation \& Dean of Enrollment Management at The Citadel, providing leadership for the institution's strategic planning, accreditation, assessment, institutional research, admissions, financial aid, and graduate college offices. She holds a Ph.D. in Higher Education Administration from the University of Arizona and master's degrees in counseling, instructional design, and human resource management.

\section{Dr. Robert J. Rabb P.E., The Citadel}

Robert Rabb is an associate professor and the Mechanical Engineering Program Director at The Citadel. He previously taught mechanical engineering at the United States Military Academy at West Point. He received his B.S. in Mechanical Engineering from the United States Military Academy and his M.S.E. and $\mathrm{PhD}$ in Mechanical Engineering from the University of Texas at Austin. His research and teaching interests are in mechatronics, regenerative power, and multidisciplinary engineering.

\section{Dr. Kevin C. Bower P.E., The Citadel}

Dr. Kevin Bower is the D. Graham Copeland Professor of Civil Engineering and Head of the Department of Civil and Environmental Engineering at The Citadel, Charleston, South Carolina. Dr. Bower's teaching research interests are in improving active learning environments and the development of classroom pedagogy to improve moral development in engineering students. 


\section{Enhancing Student Learning Through Accreditation}

Employers commonly note ethical reasoning skills as a top desired skill in college graduates. Within our own institutional context, the focus and institutional belief in the importance of ethical reasoning is even more pronounced. In addition to the mission to "educate and develop our students to become principled leaders in all walks of life by instilling the core values of The Citadel in a disciplined and intellectually challenging environment," The institution espouses three core values: Honor, Duty, and Respect. The institution's core value of honor encompasses an expectation for ethical behavior:

First and foremost, honor includes adherence to the Honor Code of The Citadel. A cadet "will not lie, cheat or steal, nor tolerate those who do." The commitment to honor extends beyond the gates of The Citadel and is a life-long obligation to moral and ethical behavior. In addition, honor includes integrity; "doing the right thing when no one is watching." Finally, honorable behavior includes exercising the moral courage to "do the right thing when everyone is watching." The Honor Code is the foundation of our academic enterprise. (The Citadel Core Values Statement $)^{2}$

In 2007, The Citadel developed a new leader development model called The Citadel Experience, which focuses on four developmental pillars essential to creating principled leaders: academics, military, fitness, and character pillar. ${ }^{3}$ The identification of ethics and character as one of the four overarching pillars of principled leadership development underscores the importance the institution places on ethical reasoning. Since the establishment of the leader development model, a cross-disciplinary committee within the institution has been working to build upon this conceptualization by identifying learning outcomes and assessments to measure growth within each pillar. Given this institutional context and the not-yet-fully-developed Leader Development Model, it is understandable that ethical reasoning emerged as the institution's Quality Enhancement Plan. The ethical reasoning skills of students were also at the forefront of discussions occurring among faculty in The Citadel's general education program. In 2010, The Citadel Core Curriculum Committee decided to review and potentially revise the institution's general education learning outcomes. In a faculty-wide survey in 2010, ethical reasoning emerged as one of the top four skills identified by faculty as a key outcome for the institution's general education program and was later adopted as an institution-wide outcome.

As a result of this context, the university developed Ethics in Action as its current Quality Enhancement Plan (QEP) for our Southern Association of Colleges and Schools Commission on Colleges (SACSCOC) reaccreditation. The goal is to infuse ethics and the ethical decision making process into the institution's leadership courses, academic programs, and co-curricular training initiatives through the teaching of ethics across the curriculum. The infusion of ethical discussions as they apply to each major with a focus on the primary industries where they are employed will support the academic honor code and result in significant gains in ethical reasoning skills. 
The Ethics in Action theme for the QEP provided additional opportunities for embedded indicators in the engineering programs' assessments, thus meeting part of the ABET requirement. Some academic programs imparted classroom discussions and scenario based problems to engage each student multiple times in their academic majors.

This paper will outline the QEP, how it is being implemented, the assessment of the implementation and improved ethical awareness, the gains in students' ethical reasoning skills, and outline the next steps for the institution's ethics curriculum.

\section{Introduction}

The Citadel has had an honor code since the mid 1950's when the new president initiated his alma mater's honor code: "A cadet will not lie, cheat, or steal nor tolerate those who do."4 The honor system is completely student run with a faculty advisor and the president providing final approval for dismissal or retaining a student. As currently written, the honor system is a single infraction model.

The Citadel experience is based on the four pillars of learning: Academics, Military, Fitness, and Character. The honor code is located under the Character pillar that has the following definition:

Principled leadership training teaches cadets the value of integrity and moral character in everyday life. The Krause Center for Leadership and Ethics oversees the four-year leader development model which integrates leadership training into the cadet curriculum and gives cadets a competitive advantage that their peers from traditional colleges don't have. ${ }^{3}$

\section{PRINCIPLED LEADER DEVELOPMENT}

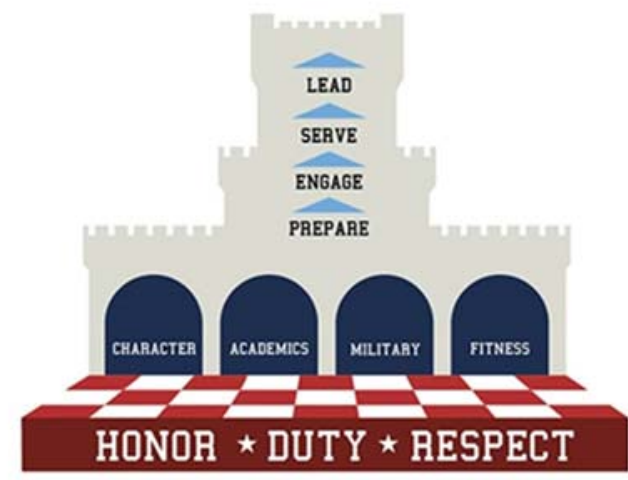

\section{THE CITADEL EXPERIENCE}

Figure 1. Principled Leader Development at The $\mathrm{Citadel}^{3}$

The Citadel has a weekly time scheduled that is part of the Leadership Training Program where some military and most Character lessons are taught and discussed to include annual honor training. Of course, portions of honor training are taught within the academic realm, especially freshman English courses, where plagiarism is discussed at length. 
Universities and colleges within the Southern Association of Colleges and Schools Commission on Colleges (SACSCOC) are required to develop a QEP as part of reaccreditation every 10 years. The Quality Enhancement Plan (QEP):

is a document developed by the institution that (1) includes a process identifying key issues emerging from institutional assessment, (2) focuses on learning outcomes and/or the environment supporting student learning and accomplishing the mission of the institution, (3) demonstrates institutional capability for the initiation, implementation, and completion of the QEP, (4) includes broad-based involvement of institutional constituencies in the development and proposed implementation of the QEP, and (5) identifies goals and a plan to assess their achievement. $^{5}$

A desire to strengthen students' ethical reasoning skills and the requirement to develop a Southern Association of Colleges and Schools Commission on Colleges (SACSCOC) Quality Enhancement Plan (QEP) for reaccreditation led to the selection of "Ethics in Action: Since 1842," as the 2014-2024 The Citadel QEP. ${ }^{6}$

\section{Quality Enhancement Plan}

The institution's QEP, Ethics in Action, embodies and supports the institution's mission to "educate and develop our students to become principled leaders in all walks of life by instilling the core values of The Citadel in a disciplined and intellectually challenging environment." The student experience is a uniquely integrated, full-immersion undergraduate program that focuses on four developmental pillars essential to creating principled leaders: academics, military, fitness, and character pillars. Through integrated curricular and cocurricular experiences, Ethics in Action is designed to transform student learning within the institution's character pillar and elevate the prominence of the leader development model.

Ethical reasoning requires individuals to possess knowledge of ethical constructs, values that guide or influence their ethical perspectives, and reasoning skills that allow them to appreciate the complexities of a scenario, and apply a process to reach a well-reasoned conclusion. Through the use of an ethical reasoning model requiring students to differentiate between moral temptations and ethical dilemmas, evaluate dilemmas using four ethical dilemma paradigms, and consider three decision principles, this QEP is designed to enhance students' ability to apply ethical reasoning skills to resolve challenging ethical dilemmas. This QEP inspires the institution to define and assess the foundational concepts communicated in its mission and core values, resulting in even greater alignment between institutional aspirations and actions.

The QEP Team received more than 50 topic ideas from the campus community and invested great efforts into narrowing these down to the three most salient ideas to enhance student learning. The three top ideas included focus areas on ethical reasoning, critical thinking, and appreciative advising. White papers were developed for each of the three ideas and evaluated for their ability to foster transformative learning opportunities, which resulted in the selection of ethical reasoning as the final topic. Within our own institutional context, the focus and institutional belief in the importance of ethical reasoning is pronounced. In addition to the 
institution's principled leadership mission, institution espouses three core values: Honor, Duty, and Respect. These core values encompass an expectation for ethical behavior. The Citadel believes that the complex society our graduates enter calls the institution to do even more in the area of developing students' ethical reasoning skills and firmly believes that the Ethics in Action QEP answers this call to do more to develop the ethical reasoning abilities of students.

Ethics in Action implementation highlights include a developmental and sequential ethical reasoning curriculum and co-curriculum that begins with an ethical reasoning common summer reading program for incoming freshmen and is followed by required courses in the freshmen, sophomore, junior, and senior years. The curriculum is supported by a series of required cocurricular leadership training program sessions in the freshmen, sophomore, junior, and senior years as well as an ethics film and speaker series. Ethics in Action implementation strategies engage students through a developmental process in which they first examine ethical issues, then consider the connection between values and ethical reasoning, next examine these issues in the context of an academic discipline or profession, then learn to differentiate between moral temptations and ethical dilemmas, and finally apply ethical reasoning to bring resolution to an ethical dilemma. The differentiation between moral temptations and true ethical dilemmas is a critically important element of the model because it provides students with a foundation to view scenarios and challenges them to elevate their decision-making beyond right versus wrong choices. Moral temptations are right versus wrong decisions where one might be tempted to choose to do the wrong thing in response to many compelling reasons. True ethical dilemmas are right versus right decisions, where students must challenge themselves by employing a decision-making protocol to assist them in choosing the rightest right. The curriculum almost exclusively concentrates on true ethical dilemmas and encourages students to avoid acting upon moral temptations. This developmental progression is supported by the integration of ethical reasoning case studies that ensure students are able to apply what they have learned. The unique military college environment also offers direct and practical application opportunities as students provide day-to-day leadership to their peers.

Ethics in Action employs seven student learning outcomes, including five cognitive outcomes and two perception outcomes:

- SLO \#1: Students will be able to identify concepts such as ethics, morals, character, ethical principles, and ethical relativism.

- SLO \#2: Students will be able to identify core values and describe the connection between values and ethical reasoning.

- SLO \#3: Students will be able to describe the impact of ethics on a profession or academic discipline.

- SLO \#4: When describing an ethical issue, students will correctly differentiate if it is a moral temptation or an ethical dilemma.

- SLO \#5: Students will be able to apply the ethical reasoning process to an ethical dilemma from their own experience.

- SLO \#6. Students will report that they believe ethical reasoning skills are an important component of being a principled leader. 
- SLO\# 7. Students will report increased confidence in their ability to apply the ethical reasoning process.

\section{Ethics in Action vs. Engineering Ethics}

Engineering has taught and used case studies for years to discuss the engineering ethics fundamental canons of the National Society of Professional Engineering (following paragraph). These canons provide guidance for engineers working within systems where the least cost and highest profit are sometimes paramount. As read, any ethical and character lessons and discussions greatly enrich the student understanding of ethics and morals while fulfilling professional duties.

"Fundamental Canons. Engineers, in the fulfillment of their professional duties, shall:

1. Hold paramount the safety, health, and welfare of the public.

2. Perform services only in areas of their competence.

3. Issue public statements only in an objective and truthful manner.

4. Act for each employer or client as faithful agents or trustees.

5. Avoid deceptive acts.

6. Conduct themselves honorably, responsibly, ethically, and lawfully so as to enhance the honor, reputation, and usefulness of the profession." 7

Each engineering program at The Citadel first covers these canons within the freshman course using case studies, with further coverage within design courses as applicable and the capstone two-course sequence. It is in the capstone that the students truly wrestle with the canons as they design a complex device or urban development, especially when room mates are on separate teams competing for the best design.

With the launch of the QEP, each of the engineering programs assessed their ethics education and made the following adjustments to their programs to link up with the requirements of the QEP.

In 2009, Civil Engineering (CIVIL) adopted much of the American Society of Civil Engineer's (ASCE) Body of Knowledge for the $21^{\text {st }}$ Century $2^{\text {nd }}$ Edition (BOK2) which is foundationally tied to The Vision for Civil Engineering in $2025^{8}$ which states that civil engineers are "Entrusted by society to create a sustainable world and enhance the global quality of life, civil engineers serve competently, collaboratively, and ethically...". The CIVIL Department adopted the following Student Outcome in response:

Student Outcome \#15: Apply standard of professional and ethical responsibility to determine an appropriate course of action. 
With this student learning outcome in place, it was easy to incorporate the requirements of the QEP into the existing curricular design. The curriculum design is as follows:

1. Freshmen - describe the ASCE and the NSPE ethical canons and reflect on them using a vignette.

2. Sophomores - explain the ASCE and the NSPE ethical canons; description of privacy, intellectual property, and truth in software as they relate to computer ethics and reflect on them using a vignette; and practice application of an ethical decision-making process through vignettes.

3. Juniors - apply the ASCE and the NSPE ethical canons to an engineering vignette. Each student submits this requirement into Taskstream, the institution's accountability management system and learning portfolio platform, as part of their writing and ethics portfolio.

4. Seniors - Design a system or process to meet desired needs within a realistic ethical constraint. This is done in the context of a two semester capstone experience.

Mechanical Engineering (MECH) was a new program at The Citadel in 2014 and referenced ASME's Vision $2030^{10}$ which stated, "Our students will need to lead not only technically but also socially, politically and ethically." Additional recommendations included ethics and professionalism integrated into the curriculum. The ME profession clearly wanted ethics education in the curriculum and assimilated in different formats and levels. Additionally, ABET requires students to "demonstrate an ability to design a system, component, or process to meet desired needs within realistic constraints such as economic, environmental, social, political, ethical, health and safety, manufacturability, and sustainability." 11 The MECH program developed a multilevel approach to meet the requirements of the QEP:

1. Freshmen - exposed to the NSPE canons and reflect on them using a workplace scenario.

2. Sophomore - exposure in the Computer Aided Design course to industry codes and standards. Other engineering courses taken this year have no specific ethics requirement for the students as they take foundational courses in other departments (Statics, Circuits).

3. Juniors - lesson devoted to engineering ethics with a short essay requirement to answer and explain a Fundamentals of Engineering style exam question (without multiple choice answers given). Each student submits this requirement into Taskstream as part of their writing and ethics portfolio.

4. Seniors - Students develop a product to meet a customer's requirements and must balance costs, schedules, product deliverables, and multiple solutions. Students are asked to identify and discuss any ethical constraints and obligations in their capstone.

Engineers may face ethical issues in the workforce, but ethical conduct must be habitual. The university must encourage students to be ethical, grow awareness of professional expectations, and stimulate discussion about ethical behavior. Students are still developing ethical habits in school, and their ethics education should be synchronous with cognitive and moral development. 


\section{Implementation over Last 5 Years}

Ethics in Action employs a developmental and sequential approach to building ethical reasoning skills. Implementation began with incoming freshmen in the summer of 2014, with curricular and co-curricular elements being phased in developmentally each year. A visual graphic of the Ethics in Action curriculum and co-curriculum is provided below.

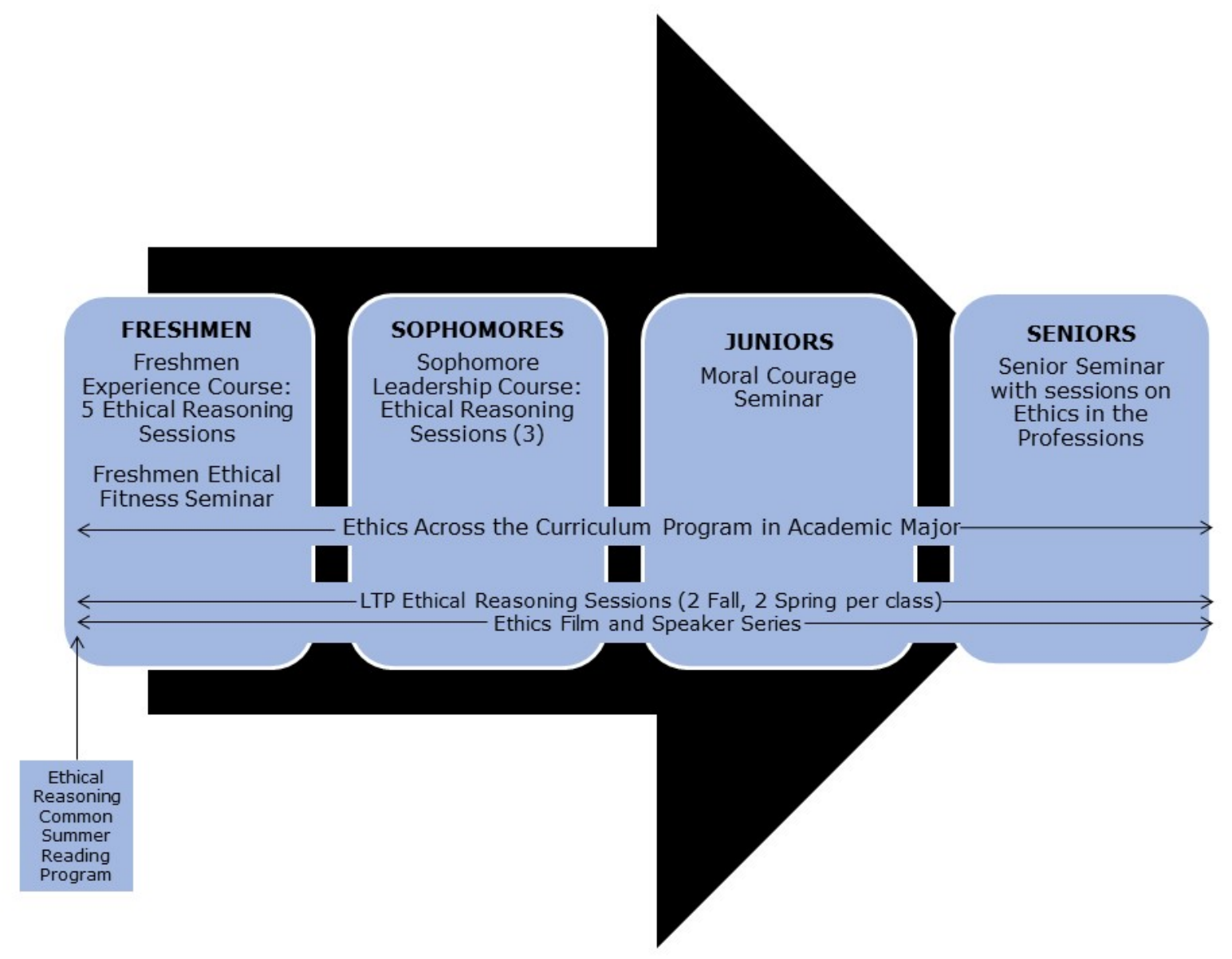

Figure 2. Ethics in Action Curriculum and Co-Curriculum

\section{Ethical Reasoning Common Summer Reading Program}

The institution has utilized a common summer reading program to focus matriculating freshmen on the topic of leadership for the last decade and has changed the focus of the program to support Ethics in Action and to better prepare incoming freshmen to discuss ethical issues in their Freshmen Experience Course. Ethics in Action utilizes the play A Few Good Men, which contains over 10 ethical dilemmas and moral temptations. The institution also designed an ethical reasoning writing assignment students must complete the summer before matriculation. 


\section{Freshmen Experience Course}

All freshmen enroll in a Freshmen Experience Course in their first term of enrollment. Five new Ethics in Action ethical reasoning class sessions have been embedded in the course designed to address SLO 1 for students to be able to identify ethical concepts and SLO 3 identifying impact on a profession. Students spend the first class session discussing ethics. In the second class session, students divide into smaller working groups to explore one of ten ethics scenarios. In a later segment of the course, students engage in a three-lesson session Library assignment where students complete an assignment researching an ethical issue that connects to one of the issues in their summer reading assignment, A Few Good Men. Students also complete a writing assignment on ethical issues and upload it to their E-Leadership Portfolio for grading with the Ethics Rubric. The E-Leadership Portfolio is an award winning four-year learning portfolio requiring every student to upload embedded course assignments that are assessed for ethical reasoning, written communication, critical thinking, and civic engagement. The portfolio enables the institution to assess individual student progress in these learning areas annually over four years as well as aggregate student growth. These sessions were implemented in fall 2014.

\section{Ethical Fitness Seminar, Freshmen Ethics Enrichment Experience}

The Freshmen Ethics Enrichment Experience, is a new required course that employs Ethical Fitness Seminar curricula designed and licensed from the Center for Global Ethics. A cadre of faculty have been trained and licensed by the Center for Global Ethics to facilitate this seminar for students. The course is comprised of ten sessions where students learn the ethical reasoning model, practice differentiating ethical dilemmas from moral temptations, and apply the ethical reasoning process to resolve an ethical dilemma, addressing SLOs 4 and 5. Students also complete a writing assignment applying the ethical reasoning process and upload it to their ELeadership Portfolio for grading with the AAC\&U Ethical Reasoning VALUE Rubric. This was implemented in the spring of 2015.

\section{$\underline{\text { Sophomore Leadership Seminar }}$}

All sophomores enroll in the Sophomore Leadership Seminar in the fall of their sophomore year. Three new Ethics in Action ethical reasoning class sessions have been embedded in the course designed to address SLO 2 for students to be able to identify the connection between values and ethics. The course utilizes the film Twelve Angry Men to examine ethical issues and the values that underpin how individuals perceive and reason with those issues. Students watch three segments of the film and then work in groups to complete an assignment analyzing the ethical issues in the film. Students also complete a midterm essay assignment where they must demonstrate their ability to connect the relationship between values and ethics. Students will upload their assignments to their E-Leadership Portfolios to be graded with the Ethics Rubric. This was implemented in the fall of 2015.

\section{Moral Courage Seminar, Junior Ethics Enrichment Experience}

All juniors enroll in the Junior Ethics Enrichment Experience, a new required course that employs the Moral Courage Seminar curricula designed and licensed from the Center for Global 
Ethics. A cadre of faculty and staff were trained in the summer of 2016. The course provides both lecture as well as group work requiring students to recognize common inhibitors to standing up for their values, making decisions aligned with ethical principles, and provides a process for employing moral courage in those circumstances. Following this seminar, students completed a required Ethical Reasoning Writing Assignment and uploaded it into their E-Leadership Portfolio for grading with the Ethics Rubric.

\section{$\underline{\text { Senior Leadership Integration Seminar }}$}

As part of the Senior Leadership Integration Seminar, students will engage in a session, entitled "Ethical Reasoning Session on The Value of My Character." This session will first engage students in a discussion of their perception of the ethical climate in the industry they have selected to pursue professionally. The course is co-facilitated by a faculty member and a local employer or alumnus, which provides valuable industry feedback to students. The session then employs an industry ethical dilemma case study in which students work in small groups to discuss the overall goal of most organizations in the industry, how the ethical dilemma relates to this goal, and possible resolutions to the dilemmas outlined in the case. Students then work as an entire seminar group to explore the impact of ethics on this profession and to assess the ethical dilemma resolution recommendations of each group. Following this seminar, students complete a required Ethical Reasoning Writing Assignment and upload it into their E-Leadership Portfolio for grading with the Ethics Rubric. This was implemented in fall of 2017.

\section{Ethics Across the Curriculum Courses}

Ethics in Action also employs an Ethics Across the Curriculum component, where every undergraduate academic degree program has specified one course in which an ethics lesson will be included that aligns with SLO 3, how ethics apply in the academic discipline or profession, as well as SLO 5, application of an ethical reasoning process. Each of these courses also requires a writing assignment that is uploaded by students to their E-Leadership Portfolios and graded utilizing the AAC\&U Ethical Reasoning VALUE rubric. Both CIVIL and MECH programs do this in the junior year as presented previously. By executing this assessment in the junior year, it allows the students to develop skills in earlier classes and ensure appropriate cognitive performance against the VALUE rubric. Some engineering programs are expanding beyond the freshman, junior and senior capstone experience as the next example presents.

In MECH 460 Mechanical System Design, there is a block of instruction on Contracts, Legal and Ethical Issues where an ethics assignment is required for homework as well as their E-

Leadership Portfolio, previously described. Students had to submit a 2-4 page paper suggesting a course of action to a scenario. They could include NSPE Canons if needed. The requirement also asked them to think about alternative responses and why they would or would not be appropriate. A recent year's scenario is below:

Julio is a design engineer working for a sheet metal fabricating firm. He is tasked with the design of a portable steel tank for compressed air to be mass produced and sold to consumers for pressurizing automobile tires. He designs a cylindrical tank to be manufactured by rolling sheet metal into a cylinder, closing with a longitudinal weld 
along the top, and welding on two elliptical heads. His design drawings are approved by his supervisor, Sonja, a licensed engineer, and by the vice president of manufacturing, but when the client reviews the designs, he asks the VP to change the design so that the longitudinal weld along the top is moved to the bottom where it will not be visible to improve the esthetics and marketability of the product. The VP agrees with this change. Julio learns of this change and objects, citing concerns about corrosion at the weld if it is on the bottom. Sonja forwards Julio's objection with a recommendation against the change to the VP, with a copy to the client, but the VP insists, saying esthetics is very important in this product. What should Julio do? ${ }^{12}$

The problem worked well to provoke thought on the effects of ethics on the engineering profession. From the freshman year course to this junior year assignment, students move beyond basic fundamental knowledge of the NSPE Canons to more nebulous situations and apply a "what if" analysis. This junior level course postures them for their own senior design project where they will have many competing requirements and still apply ethical standards.

\section{Leadership Training Program Co-Curricular Sessions}

The institution's Leadership Training Program is an important component of the curriculum, providing students with the opportunity to apply and practice leadership and ethical reasoning concepts. The program utilizes a dedicated training hour, Tuesdays at $11 \mathrm{am}$, when no academic classes are offered. Ethics in Action embeds 16 new training sessions, four sessions per class year. The sessions are designed to reinforce the concepts learned in the classroom elements of Ethics in Action and to provide an additional opportunity for application. The co-curricular component also includes a film series with an ethics film shown to each year of students. Implementation of these sessions began in academic year 2014-2015.

\section{QEP Implementation Assessment}

Ethics in Action student learning outcomes are assessed through the utilization of multiple assessment techniques, including both direct and indirect measures. Assessment techniques include student essays assessed with the Ethics in Action Rubric, Ethics Concepts Pre-Test and Post-Test, Ethics in Action Survey, and the National Survey of Student Engagement, a nationally-normed instrument.

The Ethics Concepts Pre-Test and Post-Test is a locally-developed short answer instrument that assesses students' understanding of ethical reasoning related concepts, including ethics, morals, character, ethical principles, and ethical relativism. The results indicate a significant overall gain of 14 percentage points across all concepts. Student growth in the ability to differentiate between a moral temptation and an ethical dilemma increased by $67 \%$, demonstrating the impact of the Freshmen Ethical Fitness Seminar where that skill is the focal area (Table 1). 
Table 1. The Ethics Concepts Pre-Test and Post-Test Results

\begin{tabular}{|l|r|r|r|}
\hline \multicolumn{1}{|c|}{ Ethical Concepts Test } & $\begin{array}{c}\text { Freshmen on } \\
\text { Matriculation } \\
\text { Day }\end{array}$ & $\begin{array}{c}\text { Freshmen } \\
\text { After 1 } \\
\text { Year QEP } \\
\text { Curriculum }\end{array}$ & $\begin{array}{c}\text { Difference } \\
\text { Between } \\
\text { Pre and } \\
\text { Post Test } \\
\text { Scores }\end{array}$ \\
\hline Character & $35 \%$ & $36 \%$ & $2 \%$ \\
\hline Decision Principles & $22 \%$ & $46 \%$ & $24 \%$ \\
\hline Ethical Dilemma & $66 \%$ & $77 \%$ & $11 \%$ \\
\hline Ethical Dilemma Paradigms & $34 \%$ & $57 \%$ & $23 \%$ \\
\hline Ethical Principles & $22 \%$ & $23 \%$ & $1 \%$ \\
\hline Ethical Relativism & $55 \%$ & $64 \%$ & $9 \%$ \\
\hline Ethics & $10 \%$ & $14 \%$ & $4 \%$ \\
\hline Moral & $50 \%$ & $51 \%$ & $1 \%$ \\
\hline Moral Values & $20 \%$ & $20 \%$ & $0 \%$ \\
\hline Values & $36 \%$ & $44 \%$ & $8 \%$ \\
\hline List Core Values & $75 \%$ & $95 \%$ & $20 \%$ \\
\hline $\begin{array}{l}\text { Ability to Describe the Difference Between } \\
\text { an Ethical Dilemma and Moral Temptation }\end{array}$ & $8 \%$ & $75 \%$ & $67 \%$ \\
\hline \multicolumn{1}{|c|}{ Average } & $36 \%$ & $50 \%$ & $\mathbf{1 4 \%}$ \\
\hline
\end{tabular}

The institution requires all undergraduate students to complete an E-Leadership Portfolio housed within an accountability management software system, which greatly enhances the assessment of ethical reasoning skills. The essays students produce each year are each uploaded into the accountability system and are assessed by faculty using the American Association of Colleges and Universities' (AAC\&U) Valid Assessment of Learning in Undergraduate Education (VALUE) rubric for ethical reasoning skills. This provides the institution with the ability to track individual students' ethical reasoning skill development and growth over four years as well as the aggregate results by course and class years.

The institution has adapted the AAC\&U Ethical Reasoning VALUE rubric which uses a 4-point scale to assess student learning through the evaluation of student writing assignments embedded within Ethics in Action courses. Students are required to write an ethics essay every year. Assessment results indicate a significant increase in student achievement from freshmen to senior year.

The Ethics in Action Survey is a locally-developed survey instrument that employs student selfreport data to gauge student perceptions about their achievement of the student learning outcomes. The results indicate significant growth with an average increase over $10 \%$, from freshmen to senior year in student perceptions of their own ethical reasoning abilities. The overall results are depicted in the table below (Table 3 ). 
Table 2. Ethical Reasoning Essay Results

\begin{tabular}{|l|c|c|c|}
\hline \multicolumn{3}{|c|}{ Ethical Reasoning Essay Results } \\
Assessed with AAC\&U Ethical Reasoning VALUE Rubric \\
\hline \multicolumn{1}{|c|}{ Student Learning Outcome } & Freshmen & Seniors & $\begin{array}{c}\text { Change Over } \\
\text { Time }\end{array}$ \\
\hline Ethical Concept Recognition (SLO 1) & & & \\
& 3.0 & 3.66 & $16.5 \%$ \\
\hline Application of Ethical Perspectives/Concepts (SLO 4) & & & \\
\hline Application of an Ethical Reasoning Process (SLO 5) & 3.11 & 3.57 & $11.5 \%$ \\
\hline
\end{tabular}

Table 3. The Ethics in Action Survey

\begin{tabular}{|c|c|c|c|}
\hline Student Learning Outcome & Freshmen & Seniors & $\begin{array}{c}\text { Change Over } \\
\text { Time }\end{array}$ \\
\hline $\begin{array}{l}\text { I am able to identify concepts such as } \\
\text { ethics, morals, character, ethical } \\
\text { principles, and ethical relativism. (SLO 1) }\end{array}$ & $82.1 \%$ & $92.50 \%$ & $10.41 \%$ \\
\hline $\begin{array}{l}\text { I am able to identify core values and } \\
\text { describe the connection between values } \\
\text { and ethical reasoning. (SLO 2) }\end{array}$ & $83.5 \%$ & $91.80 \%$ & $8.28 \%$ \\
\hline $\begin{array}{l}\text { I am able to describe the impact of ethics } \\
\text { on a profession or academic discipline. } \\
\text { (SLO 3) }\end{array}$ & $80.4 \%$ & $91.10 \%$ & $10.73 \%$ \\
\hline $\begin{array}{l}\text { When describing an ethical issue, I am } \\
\text { able to correctly differentiate whether it is } \\
\text { a moral temptation or an ethical dilemma. } \\
\text { (SLO 4) }\end{array}$ & $57.4 \%$ & $89.00 \%$ & $31.55 \%$ \\
\hline $\begin{array}{l}\text { I am able to apply the ethical reasoning } \\
\text { process to an ethical dilemma from my } \\
\text { own experience. (SLO 5) }\end{array}$ & $75.2 \%$ & $91.20 \%$ & $15.99 \%$ \\
\hline $\begin{array}{l}\text { I believe that ethical reasoning skills are } \\
\text { an important component of being a } \\
\text { principled leader. (SLO 6) }\end{array}$ & $96.1 \%$ & $92.10 \%$ & $-4.03 \%$ \\
\hline $\begin{array}{l}\text { I am confident in my ability to apply an } \\
\text { ethical reasoning process to solve } \\
\text { complex ethical dilemmas. (SLO 7) }\end{array}$ & $89.1 \%$ & $92.80 \%$ & $3.69 \%$ \\
\hline Average & $80.6 \%$ & $91.5 \%$ & $10.94 \%$ \\
\hline
\end{tabular}


Even though the survey results are high for both the freshmen and senior years, The Citadel is assessing all curricular components of Ethics in Action to understand why there was a decrease in the reporting for SLO6. The institution is also examining the assessment administration and timing since SLO6 scored as one of the highest elements by seniors, even though the percentage is less than those same students rated it three years previously. This is the first cohort to complete the entire program. The data depicted above represents freshmen beginning in Fall 2014 and graduating in Spring 2018.

The National Survey of Student Engagement (NSSE) also measures students' perceptions about the development and clarification of ethics. The national assessment instrument poses the following question: "During the current school year, how much have you focused on developing or clarifying a personal code of ethics?" Since the implementation of the Ethics in Action QEP, the percent of students reporting very frequently moved from $84 \%$ to $86 \%$.

\section{Lessons Learned}

Reflecting upon the implementation of Ethics in Action, there are several major lessons learned. One major lesson is that institutional investment matters. The broad-based, campus-wide involvement in developing Ethics in Action strengthened the entire process, which included examining assessment data, conducting research, soliciting topic ideas, refining the selected topic into meaningful and measurable learning outcomes, developing curriculum and assessments, and building a communication and implementation action plan. A second major lesson learned was the value and importance of implementing programs that are closely aligned with core values and mission of the institution. This alignment enabled Ethics in Action to be embedded in the core of the institution's ethos. Building upon existing strengths to drive student learning also made a major impact. The Ethics in Action program to date has noted the most significant gains in student achievement where learning outcomes have been embedded within semester long classes, enabling more application and repetition. This enables the institution of use existing course and program review processes to review the assessment data and make continuous improvement curricular enhancements.

University programs, especially in engineering, must conduct ethics education to prepare students for work and professional licensure. Instruction in ethics may be topics within courses or more structured as in an honor code and academic conduct. These practices should enable career-long development of ethics knowledge and judgment.

\section{Ethics in Action Path Forward}

Ethics in Action utilized a phased in approach for curriculum and co-curricular implementation, implementing freshmen components in 2014, sophomore components in 2015, junior components in 2016, and senior components in 2017. The institution is actively building upon the assessment findings from this first cohort to implement continuous improvements within the curriculum that will positively impact subsequent cohort groups.

The institution will also use lessons learned and data from Ethics in Action when conceptualizing the topic for its next Quality Enhancement Plan in 2024. 


\section{References}

1. http://155.225.198.23/root/mission-statement

2. http://www.citadel.edu/root/core-values

3. The Citadel Honor Code, http://www.citadel.edu/root/images/krause center/honor/honormanual20172018\%207.11.17\%20final.pdf

4. The Citadel Four Pillars, http://www.citadel.edu/root/cadet-admissions

5. SACSCOC QEP, http://www.sacscoc.org/QEPSummaries.asp

6. The Citadel SACSCOC QEP, http://www.citadel.edu/root/ethics-in-action

7. Engineering Canons, National Society of Professional Engineers, June 1954

8. The Vision for Civil Engineering in 2025, American Society of Civil Engineers, 2007

9. Civil Engineering Body of Knowledge for the $21^{\text {st }}$ Century, $2^{\text {nd }}$ edition, American Society of Civil Engineers, 2008

10. ASME Vision 2030, https://community.asme.org/board education/w/wiki/7883.asme-vision2030-project.aspx

11. ABET, retrieved from http://www.abet.org

12. Kaplan, "Fundamentals Of Engineering FE/EIT Exam Preparation, 19 ${ }^{\text {th }}$ Edition," Kaplan Engineering Education, LaCrosse, WI, 2011. 